Um estudo sobre o Physica, de Hildegarda de Bingen: as virtudes curativas de algumas plantas

\author{
Maria Terezinha Estevam·
}

Dissertação de Mestrado

Pontifícia Universidade Católica de São Paulo, Brasil

\begin{abstract}
Resumo
A Abadessa da ordem beneditina Hildegarda de Bingen, em meados do século XII, compôs a obra Physica, um livro de remédios simples no qual discorre sobre receitas curativas utilizando as coisas naturais. No livro primeiro do Physica, o De Plantis, Hildegarda descreveu como tratar os mais diferentes problemas de enfermidades por meio das virtudes curativas das plantas. O Physica é o resultado do estudo e da prática de cura da Abadessa. Conforme sugerem pesquisas em História da Ciência, ela faz uma espécie de fusão entre três diferentes tradições, encontradas no território germânico medieval, sendo elas: a tradição cristã latina, a tradição popular germânica e o conhecimento médico greco-romano. Outro aspecto que consideramos ter influenciado no saber de cura da Abadessa foi sua forma complexa e própria de ver o mundo que a rodeava, típica do pensamento místico medieval. Este trabalho mostra evidências desses aspectos de influências no saber médico de Hildegarda, a partir da análise e descrição de algumas plantas encontradas no primeiro capítulo do Physica. Com isso, esperamos contribuir para os estudos sobre Hildegarda de Bingen no campo da História da Ciência.
\end{abstract}

\title{
Palavras chaves
}

História da Ciência; Hildegarda de Bingen; Herbários medievais; Mística medieval

• mtestevam024@gmail.com. 